\title{
The Impact of Fixed Orthodontic Therapy in Correction of Malocclusion in Adults
}

\author{
Ângela Cristina Pinto de Paiva Cunha1 ${ }^{*}$, Olga Benário Vieira Maranhão², \\ Ana Gláucia de Oliveira Macedo ${ }^{2}$, Anderson Farias da Cunha ${ }^{2}$, Kenio Costa de Lima ${ }^{1}$ \\ ${ }^{1}$ Department of Dentistry, Federal University of Rio Grande do Norte, Natal, Brazil \\ ${ }^{2}$ Rehabilitation Hospital of Craniofacial Anomalies of São Paulo University (HRAC-USP), Bauru, Brazil \\ Email: *angelapinto9@gmail.com, olgamaranhao@hotmail.com, anna_glaucia@hotmail.com, \\ afcnatal@hotmail.com, limke@uol.com.br
}

Received 20 March 2015; accepted 4 April 2015; published 9 April 2015

Copyright (C) 2015 by authors and OALib.

This work is licensed under the Creative Commons Attribution International License (CC BY).

http://creativecommons.org/licenses/by/4.0/

(c) (i) Open Access

\begin{abstract}
Objective: To measure the impact of fixed orthodontic therapy in the correction of malocclusion in adults and to evaluate the influence of factors associated with this impact. Methods: The sample consisted of $\mathbf{2 8 8}$ adult patients who had undergone fixed orthodontic therapy. The adequacy of orthodontic treatment was assessed by the PAR index in models of initial and final study. Associated factors were divided into two groups: socio-economic demographic variables (gender, education level, type of service, age at end of treatment), and the independent orthodontic variables (DHC-IOTN, AC-IOTN, satisfactory use of retainer, conducting speech therapy, and main complaints). For data analysis, we used the chi-square tests and multivariate logistic regression for a confidence level of $95 \%$. Results: Independent of associated factors, the improvement of the treated cases was greater than $\mathbf{8 8 . 2 \%}$ of the sample, with significant improvement in cases with moderate or severe initial need of treatment $(p=0.008)$ and in patients older than 25 years at the time of treatment $(p=0.015)$. Conclusion: The orthodontic therapy resulted in significant improvement, especially in cases with moderate or severe orthodontic treatment need and in adults over the age of 25 years.
\end{abstract}

\section{Keywords}

Orthodontics, Corrective, Index of Orthodontic Treatment Need, Orthodontics

Subject Areas: Dentistry

\section{Introduction}

How does one assess the outcome of orthodontic therapy? What is the gold standard that will serve as a guide Corresponding author.

How to cite this paper: Cunha, A.C.P., Maranhão, O.B.V., Macedo, A.G.O., da Cunha, A.F. and de Lima, K.C. (2015) The Impact of Fixed Orthodontic Therapy in Correction of Malocclusion in Adults. Open Access Library Journal, 2: e1427. http://dx.doi.org/10.4236/oalib.1101427 
for the conclusion of treatment? What is the real improvement/impact even after orthodontic treatment on the quality of life of individuals? To address some of these questions, there have been several quantitative indices used for assessing the need for orthodontic treatment or the results thereof reported in the literature [1]-[6]. Otuyemi and Jones (1995) [2] performed a review of the different methods to evaluate a malocclusion or correction thereof, and the indices were divided into 5 groups: diagnostic, epidemiology, treatment needs, treatment success, and complexity of treatment.

Although there is controversy in the use of occlusal indices with respect to their use in clinical practice, their development and more specifically near ideal characteristics are of great importance for the correct assessment of the epidemiological situation of oral health, both in pre- and post-orthodontic treatment, and appropriate implementation is preventative and curative action. Studies show that malocclusion has high and increasing prevalence, justifying the need for more reliable epidemiological surveys due to the limited resources for treatment and the difficulty for the clinician to diagnose it properly and assess its severity on a large scale. Thus, necessitating the use of a valid instrument of occlusal indices has been envisaged aiming to categorize the indications and prioritization of orthodontic treatment and the outcome of this therapy [6]-[8].

Historically, this has been a careful task, mainly to reliably and satisfactorily assess the results of orthodontic treatments in epidemiological studies. An assessment of the need for orthodontic treatment and immediate results, as well as long-term cases of orthodontic treatment has been of interest for many decades.

The PAR index was created in the 80's at the University of Manchester, in order to objectively verify the quality of orthodontic treatment. The measurement of the level of improvement achieved with the treatment is performed by a single score that summarizes all occlusal features present, obtained by considering five components in the analysis models: a previous segment, buccal segments, overjet, overbite, and midline [9] [10]. The same is designed to provide a way of quantifying the success of the orthodontic treatment [6] [11]-[14]. The final percentage obtained with a higher average value of at least $70 \%$, indicates satisfactory improvement with orthodontic treatment, and is considered as a good standard of quality [15].

The clinical significance is to attract attention to the need to evaluate other orthodontic post-treatment vestments and motivate patients in search of them, such as: what is the cost benefit of doing orthodontic treatment? Does only the search for aesthetic and functional improvements lead patients in seeking orthodontic treatment? What is the impact of this treatment on quality of life of adults, depending on age, as the aesthetic issue does not always prevail in adults compared to children and teenagers?

With this assumption, this study aimed to evaluate the impact of fixed orthodontic therapy in the correction of malocclusion in adults, and to evaluate the influence of factors associated with this impact.

\section{Methods}

This study evaluated 288 adults undergoing fixed orthodontic therapy, aged between 20 - 70 years. The study population was selected from graduate courses offered by the Academy of Dentistry of Rio Grande do Norte and Brazilian Dental Association of Rio Grande do Norte-ABO/RN, and private offices that make up the cases treated in private schools in 2013.

The dependent variable for this study was the impact of orthodontic treatment for the correction of malocclusion, as assessed by the difference between initial PAR and final PAR. To this end, this variable was dichotomized using the median value score of 13, with below 13 considered as having little impact on the correction. Consequently, values greater than 13 had significant impacts on correcting malocclusions.

The PAR occlusal index was used to quantitatively evaluate the intra-arch and interarchocclusal relationships observed in the study models pre- and post-treatment. The PAR index, calculated from 11 occlusal component reviews: right-upper segment, anterior-superior segment, upper-left segment, lower-right segment, anterior-inferior segment, lower-left segment, right-posterior occlusion, left-posterior occlusion, overjet, overbite, and midline. The difference between the initial and final values of the PAR index was calculated to express the amount of percentage improvement resulting from the treatment. The PAR index cannot measure iatrogenic effects, such as enamel lesions, bone loss, or apical root resorption.

Prior to analysis of study models, there was calibration of examiners in order to ensure uniformity of interpretation, understanding, application of IOTN occlusal indices (Index of Orthodontic Treatment Need) and PAR. For this purpose, the first step in the study of criteria for data collection consisted of studying models, through discussion of articles and explanation of each occlusal index. The second phase consisted of a pilot study whose 
objective was to provide examiners an establishment of the criteria for analysis and measurement of occlusal indices. An external examiner for research had previously selected 30 study models with several instances of malocclusions, practicing on models aiming to collect data indices that measure malocclusions to be adopted in the study. Subsequently, the examiners performed the tests, and after they were completed, they checked the differences that occurred. The models which had valuation differences observed between the examiners were reexamined and reservations resolved.

After this phase, there was the inter-calibration. This calibration was also performed in this pilot study assessing 30 study models. After occlusal indices were reviewed, arrays were assembled to verify the agreement and allow the calculation of kappa or weighted kappa coefficient, considering each index separately. The acceptable standard kappa value equal to or greater than 0.80 in each of the indices evaluated was considered. Therefore, the lowest kappa value obtained in this step was greater than 0.86 for all variables studied.

The independent variables were divided into two groups: socio-economic demographic variables (gender, education level, type of service, age at end of treatment) and the independent orthodontic variables (DHC-IOTN, AC-IOTN, satisfactory use of retainer, conducting speech therapy, and main complaints).

The IOTN index ranks the need for orthodontic treatment according to the importance and severity of various occlusal characteristics and oral health functions according to the perceived aesthetic damage, with only the highest severity of their occlusal scale being noted. It consists of two distinct components, the component of dental health (DHC) and aesthetic component (AC), which is assessed by the SCAN [14] scale. The DHC-IOTN is an attempt to synthesize all possible harmful effects of malocclusions in a reproducible and objective method of evaluation. In it, all occlusal characteristics judged as interfering in the life and function of the occlusion were classified on a scale of five grades, with increasing order of need for treatment. For assistance identifying the worst feature, a hierarchy of occlusal anomalies was developed to determine which one would be recorded, while the AC is measured from a scale with ten photographs ranging from grade 1 - 10, in which the first reflects a greater degree of dental attractiveness, while the latter portrays a great need for aesthetic improvement [14]. The purpose of the scale is not to simply find a similar comparative smile for the individual, but the smile placed in the extremes of appearance (score 1 - the best appearance and score 10 - the worst appearance).

Initially, a descriptive analysis of all variables was performed at the expense of measures of absolute and relative frequency, as well as statistical indices that summarize the data. For data analysis, aiming to relate factors associated with PAR, a bivariate analysis was performed using the chi-square test. To know the independent associated factors that influence the impact of the difference in initial and final PAR, there was multiple logistic regression analysis. For this, they recruited the variables whose p value was less than or equal to 0.20 for the hierarchical modeling, grouping them into blocks, set by the Hosmer and Lemeshow test for a confidence level of $95 \%$.

This paper was written after authorization of Research Ethics Committee (CEP) of Federal University of Rio Grande do Norte (number 002/11-P N CEP/UFRN). The study was made in bases of ethical principles.

\section{Results}

The results of the categorization of the sample are shown in Table 1, where women with a high level of education predominated in this study. Most had moderate or high need for treatment by DHC-IOTN; the most common main complaint was bad tooth position; the vast majority did not do complementary speech therapy; satisfactory use of retainer with a minimum of 12 months after the removal of braces.

Of the independent variables of the study, only the need for orthodontic treatment and final age were associated with the impact of the correction of malocclusions (Table 2). Patients who had moderate or severe need of treatment and age greater than 25 years benefited the most from fixed orthodontic therapy.

The results of multivariate analysis showed that independent of other socio-economic demographic and orthodontic variables, the need for moderate to severe orthodontic treatment and final age after orthodontic treatment were associated with a greater impact on correcting malocclusions (Table 3).

The impact of the correction was $88.2 \%$, where the variables investigated showed that interfering with the impact were high or moderate need for treatment, according to DHC-IOTN, and final age over 25 years after orthodontic treatment. The combination of factors that could influence the impact is not statistically significant.

\section{Discussion}

The PAR index represents the dento-occlusal variation which exists before and after treatment, and is widely 
Table 1. Characteristics of the sample according to socio-economic demographic and orthodontic variables.

\begin{tabular}{|c|c|c|c|}
\hline & Variables & $\mathbf{n}$ & $\%$ \\
\hline \multirow{2}{*}{ Gender } & Female & 166 & 57.6 \\
\hline & Male & 122 & 42.4 \\
\hline \multirow{3}{*}{ Instruction level } & High school & 75 & 26.0 \\
\hline & Incomplete higher education & 40 & 13.9 \\
\hline & Higher education & 173 & 60.1 \\
\hline \multirow{2}{*}{ Kind of service } & Public & 136 & 47.2 \\
\hline & Private & 152 & 52.8 \\
\hline \multirow{2}{*}{ Final age } & Until 25 years & 138 & 47.9 \\
\hline & $>25$ years & 150 & 52.1 \\
\hline \multirow{2}{*}{ DHC-IOTN } & Without or low need & 109 & 37.8 \\
\hline & Moderate or high need & 179 & 62.2 \\
\hline \multirow{2}{*}{ AC-IOTN } & Without or low need & 160 & 55.6 \\
\hline & Moderate or high need & 128 & 44.4 \\
\hline \multirow{4}{*}{ Chief complaint } & Bad tooth position & 152 & 52.8 \\
\hline & Space between teeth & 93 & 32.3 \\
\hline & Deformity of the mouth and face & 22 & 7.6 \\
\hline & Others & 21 & 7.3 \\
\hline \multirow{2}{*}{ Speech therapy } & Yes & 89 & 30.9 \\
\hline & No & 199 & 69.1 \\
\hline \multirow{2}{*}{ Satisfactory use of restraint } & Yes & 256 & 88.9 \\
\hline & No & 32 & 11.1 \\
\hline
\end{tabular}

used internationally, as it is reproducible, valid, and usually chosen to investigate treatment outcomes in crosssectional and longitudinal studies [14] [16] [17].

As the main objective of this study was to evaluate the level of improvement of 288 treated cases, there was a review of socio-economic demographic variables (gender, education level, type of service, and age at end of treatment) and orthodontic (DHC-IOTN, AC-IOTN, main complaint, conducting speech therapy, satisfactory use of retainer), in order to study the effect of these variables on the results of the impact of the correction. The type of mechanics used and type of initial malocclusion variables were not considered in seeking the percentage of improvement in terms of population in light of the study, regardless of how the therapy was performed or what type of malocclusion in each patient [18] [19]. The fact that the cases were not handled by a single professional could also generate disparity in the quality of orthodontic treatment, which does not influence the results, as shown in several studies [16] [20]-[22]. Still, according to Dyken and Cols (2001) [11], there existed no difference in the quality of significant cases treated by specialists or students of Orthodontics, thus confirming the results found in this study, where the majority of treated cases independent of those who treated them had upper-occlusal improvements of $80 \%$.

The literature is scarce in studies assessing the impact of orthodontic treatment on quality of life in adults, especially in scoring the relevance of this impact as one of the factors that motivate the search for this therapy. The improvement in quality of life is significant, but it is not a common complaint reported by the patient. Quantify aesthetic and functional improvements only in traditional orthodontic records are not enough to address the impact of the presence or absence of malocclusion in the quality of life of these patients.

According to Richmond et al. (1992) [15], a good standard of orthodontic treatment should result in a reduction of the average PAR index of $70 \%$ or more. In the present study, the mean reduction of the PAR index with treatment was $88.2 \%$, featuring a good standard of orthodontic finishing treatment, regardless of the service, 
Table 2. Absolute frequency, percentage, significance, prevalence ratio and CI (95\%) over the independent variables of the study.

\begin{tabular}{|c|c|c|c|c|c|c|c|c|}
\hline \multicolumn{9}{|c|}{ Diferences between PAR incial-PAR final } \\
\hline Variables & Categories & $\begin{array}{l}\text { Little } \\
\text { impact }\end{array}$ & $\%$ & $\begin{array}{l}\text { A lot of } \\
\text { impact }\end{array}$ & $\%$ & $\mathrm{p}$ & $\mathrm{RP}$ & IC (95\%) \\
\hline \multirow{2}{*}{ Gender } & Female & 93 & $56.0 \%$ & 73 & $44.0 \%$ & 0.461 & 1.085 & $0.872-1.350$ \\
\hline & Male & 63 & $51.6 \%$ & 59 & $48.4 \%$ & & & \\
\hline \multirow{3}{*}{ Instruction level } & Higher education & 89 & $51.4 \%$ & 84 & $48.6 \%$ & 0.459 & 1.000 & - \\
\hline & $\begin{array}{l}\text { Incomplete higher } \\
\text { education }\end{array}$ & 45 & $60.0 \%$ & 30 & $40.0 \%$ & & 1.214 & $0.884-1.666$ \\
\hline & High school & 22 & $55.0 \%$ & 18 & $45.0 \%$ & & 1.079 & $0.741-1.571$ \\
\hline \multirow{2}{*}{ Kind of service } & Public & 75 & $55.1 \%$ & 61 & $44.9 \%$ & 0.752 & 1.035 & $0.837-1.280$ \\
\hline & Private & 81 & $53.3 \%$ & 71 & $46.7 \%$ & & & \\
\hline \multirow{2}{*}{ Final age } & Until 25 years & 85 & $61.6 \%$ & 53 & $38.4 \%$ & 0.015 & 1.301 & $1.050-1.612$ \\
\hline & $>25$ years & 71 & $47.3 \%$ & 79 & $52.7 \%$ & & & \\
\hline \multirow[b]{2}{*}{ DHC-IOTN } & Without or low need & 70 & $64.2 \%$ & 39 & $35.8 \%$ & 0.008 & 1.337 & $1.087-1.644$ \\
\hline & $\begin{array}{l}\text { Moderate or high } \\
\text { need }\end{array}$ & 86 & $48.0 \%$ & 93 & $52.0 \%$ & & & \\
\hline \multirow[b]{2}{*}{ AC-IONT } & Without or low need & 93 & $58.1 \%$ & 67 & $41.9 \%$ & 0.132 & 1.181 & $0.948-1.471$ \\
\hline & $\begin{array}{l}\text { Moderate or high } \\
\text { need }\end{array}$ & 63 & $49.2 \%$ & 65 & $50.8 \%$ & & & \\
\hline \multirow{3}{*}{ Chief complaint } & Space between teeth & 57 & $61.3 \%$ & 36 & $38.7 \%$ & 0.190 & 1.000 & - \\
\hline & Bad tooth position & 75 & $49.3 \%$ & 77 & $50.7 \%$ & & 1.309 & $0.969-1.767$ \\
\hline & $\begin{array}{l}\text { Deformity of the } \\
\text { mouth and face }\end{array}$ & 12 & $54.5 \%$ & 10 & $45.5 \%$ & & 1.114 & $0.687-1.808$ \\
\hline \multirow{2}{*}{$\begin{array}{c}\text { Speech and } \\
\text { Hearing therapy }\end{array}$} & Yes & 50 & $56.2 \%$ & 39 & $43.8 \%$ & 0.647 & 1.055 & $0.842-1.321$ \\
\hline & No & 106 & $53.3 \%$ & 93 & $46.7 \%$ & & & \\
\hline \multirow{2}{*}{$\begin{array}{l}\text { Satisfactory use } \\
\text { of restraint }\end{array}$} & No & 15 & $46.9 \%$ & 17 & $53.1 \%$ & 0.380 & 0.851 & $0.579-1.251$ \\
\hline & Yes & 141 & $55.1 \%$ & 115 & $44.9 \%$ & & & \\
\hline
\end{tabular}

Table 3. Absolute frequency, percentage, statistical significance, prevalence ratio and CI (95\%) of the independent variables of the study adjusted for the impact of the correction of malocclusion from the multiple logistic regression.

\begin{tabular}{|c|c|c|c|c|c|c|c|c|c|}
\hline Variable & Categories & Little (\%) & A lot (\%) & $\mathrm{RP}$ & $\mathrm{p}$ & IC (95\%) & RPaj & $\mathrm{p}$ & ICaj (95\%) \\
\hline \multirow{2}{*}{$\begin{array}{l}\text { DHC- } \\
\text { IONT }\end{array}$} & $\begin{array}{l}\text { Without or } \\
\text { low need }\end{array}$ & 70 (64.2\%) & 39 (35.8\%) & 1.337 & 0.008 & $1.087-1.644$ & 1.305 & 0.019 & $1.046-1.629$ \\
\hline & $\begin{array}{l}\text { Moderate } \\
\text { or high } \\
\text { need }\end{array}$ & $86(48.0 \%)$ & 93 (52.0\%) & & & & & & \\
\hline \multirow{2}{*}{$\begin{array}{l}\text { Age } \\
\text { final }\end{array}$} & $\begin{array}{l}\text { Until } 25 \\
\text { years }\end{array}$ & 85 (61.6\%) & 53 (38.4\%) & 1.301 & 0.015 & $1.050-1.612$ & 1.257 & 0.045 & $1.005-1.573$ \\
\hline & >25 years & 71 (47.3\%) & 79 (52.7\%) & & & & & & \\
\hline
\end{tabular}

where the treatment was performed, or the professional who conducted the case. This certainly seems to be what is subjectively called a clinically acceptable outcome [15] [23] [24]. However, the results related to the correction during treatment in this study vary compared to other studies, such as Linklater and Fox (2002) [23], who found a reduction of 68.6\% of PAR after treatment, and Dyken, Sadowsky and Hurst (2001) [11] -79.5\% for those treated by specialists certified by the American Board of Orthodontics, and 68.6\% for those treated by postgraduate students in orthodontics. But Woods, Lee, and Crawford [25] found an average reduction of 85.6\% 
and Otuyemi and Jones [2] found a correlation of 82.5\% [10] [23]. This can be explained by the differences between samples and methodologies [26].

There is certain unanimity in clinical practice and in the literature regarding the importance of cooperation with the passive and active treatment (retention phase), conducting speech therapy, and patient motivation for treatment for the final outcome, where success is based on the final quality and the time it took to achieve the result [10] [21] [27] [28]. In this study, the factors that could influence the outcome, such as cooperation (satisfactory use of retainer), conducting speech therapy, and treatment period (meaning 30 months), were evaluated by the inclusion of questionnaires regarding these aspects, and did not show significant association. An important and significant factor when evaluating the end result was the significant association with age, i.e., patients older than 25 years had more significant improvements with orthodontic treatment, in a function that the treatments from this age group were more complex than at earlier ages.

The method of assessment was chosen as the study model in order to achieve the purpose of this study and analyze occlusal outcomes of orthodontic treatments. Despite this, not allowing the clinical and radiographic analysis, the study models, per se, gather the greatest amount of information regarding orthodontic diagnosis and treatment [29]. Furthermore, we have demonstrated a poor association between occlusal characteristics and morphology obtained by radiographs, and better prediction of orthodontic results through occlusal indices than by cephalometry. It should also be noted that the amount of crowding and transverse relationship of the dental arches, cannot be evaluated by cephalometry [29] [30].

The optimal cut-off point for determining the need for orthodontic treatment using the PAR index, based on the opinions of experts for white individuals, is a score of 17 for both the United States and the United Kingdom [3]. Based on the Brazilian population having a more demanding profile for body esthetics, the cut-off for the PAR index in this study was 13, having a significant association with the DHC-IOTN. According to the DHCIOTN, cases categorized as moderate to severe need of treatment showed a more significant improvement than cases with little or no need for orthodontic treatment, emphasizing that the higher the initial need for orthodontic therapy, the greater the percentage of correction after therapy.

Although the PAR index provides a reliable assessment of the occlusal position and results of orthodontic treatment, this index does not allow, with its absolute value, the specification of which occlusal characteristics contributed most to the observed changes. This is because the PAR index is the resulting sum of scores given to different occlusal characteristics [3]. Furthermore, each of these occlusal characteristics were evaluated and multiplied by different weights, further hindering the visualization of real participation of each of the components of the index in its final [3] value.

Despite the legacy of the six keys for normal occlusion of Andrews (1972) [28], based on studies with 120 models, they represent one of the most valuable parameters for obtaining an ideal static occlusion. Consequently, a satisfactory result at the end of orthodontic treatment does not categorize the degree of improvement or the impact of this correction. Thus, the use of occlusal indices that measure how the occlusal relationships deviate from normality and how these deviations are regulated is an important tool for research on the effectiveness of orthodontic treatment.

\section{Conclusions}

The results with the fixed orthodontics are excellent in correcting the various types of occlusal problems regardless of the degree of severity. The study evaluated the degree of impact on quality of life of patients undergoing this therapy, whereas in the post-orthodontic treatment, the physical improvements are routinely evaluated only in orthodontic documentation, without having a parameter to evaluate the post-treatment on quality benefit of patients' life.

From the results obtained in this study, taking into account the criteria of the PAR Index, orthodontic treatment resulted in significant improvement, especially in cases of young adults with moderate or severe orthodontic treatment need.

\section{References}

[1] Daniels, C. and Richmond, S. (2000) The Development of the Index of complexity, Outcome and Need (ICON). British Journal of Orthodontics, 27, 149-162. http://dx.doi.org/10.1093/ortho/27.2.149

[2] Otuyemi, O.D. and Jones, S.P. (1995) Methods of Assessing and Grading Malocclusion: A Review. Australian Ortho- 
dontic Journal, 14, 21-27.

[3] Von Bremen, J. and Pancherz, H. (2003) Efficiency of Class II Division 1 and Class II Division 2 Treatment in Relation to Different Treatment Approaches. Seminars in Orthodontics, 9, 87-92. http://dx.doi.org/10.1053/sodo.2003.34028

[4] Harrison, J.E. (2000) Evidence-Based Orthodontics: Where Do I Find the Evidence? American Journal of Orthodontics, 27, 71-78. http://dx.doi.org/10.1093/ortho/27.1.71

[5] Liu, Z., McGrath, C. and Hagg, U. (2009) The Impact of Malocclusion/Orthodontic Treatment Need on the Quality of Life. Angle Orthodontist, 79, 585-591. http://dx.doi.org/10.2319/042108-224.1

[6] Kuroda, S., Fuji, A., Sugie, M., Uoi, S., Kondo, R., et al. (2010) Relationship between Orthodontic Expertise and Perception of Treatment Needs for Maxillary Protrusion: Comparison of Dental Students, Residents, and Orthodontists. American Journal of Orthodontics and Dentofacial Orthopedics, 137, 340-345. http://dx.doi.org/10.1016/j.ajodo.2008.04.029

[7] Hassam, A.H. and Aminb, H.E.-S. (2010) Association of Orthodontic Treatment Needs and Oral Health-Related Quality of Life in Young Adults. American Journal of Orthodontics and Dentofacial Orthopedics, 137, 42-47. http://dx.doi.org/10.1016/j.ajodo.2008.02.024

[8] Ekuni, D., Takeuchi, N., Furuta, M., Tomofuji, T. and Morita, M. (2011) Relationship between Malocclusion and Heart Rate Variability Indices in Young Adults. Methods of Information in Medicine, 50, 358-363. http://dx.doi.org/10.3414/ME10-01-0045

[9] Silvola, A.S., Rusanen, J., Tolvanen, M., Pirttiniemi, P. and Lahti, S. (2012) Occlusal Characteristics and Quality of Life before and after Treatment of Severe Malocclusion. European Journal of Orthodontics, 34, 704-709. http://dx.doi.org/10.1093/ejo/cjr085

[10] Joury, E., Marcenes, W. and Johal, A. (2011) The Role of Psychosocial Factors in Predicting Orthodontic Treatment Outcome at the End of 1 Year of Active Treatment. European Journal of Orthodontics, 35, 205-215. http://dx.doi.org/10.1093/ejo/cjr111

[11] Dyken, R.A., Sadowsky, P.L. and Hurst, D. (2001) Orthodontic Outcomes Assessment Using the Peer Assessment Rating Index. Angle Orthodontist, 71, 164-169.

[12] Fadiga, M.S., Diouf, J.S., Diop, Ba.K, Gueye, I., Ngom, P.I. and Diagne, F. (2014) The PAR Index for Evaluation of Treatment Outcomes in Orthodontics: A Clinical Audit of 50 Cases. International Orthodontics, 12, 84-99. http://dx.doi.org/10.1016/j.ortho.2013.12.013

[13] Deguchi, T., Honjo, T., Fukunaga, T., Miyawaki, S., Roberts, W.E., et al. (2005) Clinical Assessment of Orthodontic Outcomes with the Peer Assessment Rating, Discrepancy Index, Objective Grading System, and Comprehensive Clinical Assessment. American Journal of Orthodontics and Dentofacial Orthopedics, 127, 434-443. http://dx.doi.org/10.1016/j.ajodo.2004.03.030

[14] Ashish, A., Sadashiva, S.K., Kishore, M.S.V., Sidhu, M.S. and Navin, F. (2010) Evaluating Orthodontic Treatment Using PAR \& IOTN Indices. Journal of Pierre Fauchard Academy, 24, 85-94.

[15] Richmond, S., Shaw, W.C., Roberts, C.T. and Andrews, M. (1992) The PAR Index (Peer Assessment Rating): Methods to Determine Outcome of Orthodontic Treatment in Terms of Improvement and Standards. European Journal of Orthodontics, 14, 180-187. http://dx.doi.org/10.1093/ejo/14.3.180

[16] Ponduri, S., Pringle, A., Illing, H. and Brennan, P.A. (2011) Peer Assessment Rating (PAR) Index Outcomes for Orthodontic and Orthognathic Surgery Patients. British Journal of Oral and Maxillofacial Surgery, 49, 217-220. http://dx.doi.org/10.1016/j.bjoms.2010.03.009

[17] Rusanen, J., Silvola, A.S., Tolvanen, M., Pirttiniemi, P., Lahti, S. and Sipilä, K. (2012) Pathways between Temporomandibular Disorders, Occlusal Characteristics, Facial Pain, and Oral Health-Related Quality of Life among Patients with Severe Malocclusion. European Journal of Orthodontics, 34, 512-517. http://dx.doi.org/10.1093/ejo/cjr071

[18] Kerosuo, H., Väkiparta, M., Nyström, M. amd Heikinheimo, K. (2008) The Seven-Year Outcome of an Early Orthodontic Treatment Strategy. Journal of Dental Research, 87, 584-588.

[19] Firestone, A.R., Beck, F.M., Beglin, F.M. and Vig, K.W. (2002) Evaluation of the Peer Assessment Rating (PAR) Index as an Index of Orthodontic Treatment Needs. American Journal of Orthodontics and Dentofacial Orthopedics, 122, 463-469. http://dx.doi.org/10.1067/mod.2002.128465

[20] de Oliveira Melo, A.C.E., Carneiro, L.O.T., Pontes, L.F., Cecim, R.L., Mattos, J.N.R. and Normando, D. (2013) Factors Related to Orthodontic Treatment Time in Adult Patients. Dental Press Journal of Orthodontics, 18, 59-63.

[21] Manosudprasit, M., Wangsrimongkol, T. and Danthumrongkul, S. (2011) The Final Orthodontic Treatment Outcome Evaluation in Patients with Cleft Lip and Palate at KhonKaen University Cleft Lip and Palate Center: A Pilot Study. Journal of the Medical Association of Thailand, 94, 21-26.

[22] Park, H., Boley, J.C., Alexander, R.A. and Buschang, P.H. (2010) Age-Related Long-Term Posttreatment Occlusal and 
Arch Changes. Angle Orthodontist, 80, 247-253. http://dx.doi.org/10.2319/042109-226.1

[23] Linklater, R.A. and Fox, N.A. (2002) The Long-Term Benefits of Orthodontic Treatment. British Dental Journal, 192, 583-587. http://dx.doi.org/10.1038/sj.bdj.4801433

[24] Richmond, S. and Andrews, M. (1993) Orthodontic Treatment Standards in Norway. European Journal of Orthodontics, 15, 7-15. http://dx.doi.org/10.1093/ejo/15.1.7

[25] Woods, M., Lee, D. and Crawford, E. (2000) Finishing Occlusion, Degree of Stability and the PAR Index. Australian Orthodontic Journal, 16, 9-15.

[26] Camardella, L.T., Janson, G., Araki, J.D.V., Freitas, M.R. and Pinzan, A. (2010) A influência do protocolo de extração de dois pré-molares superiores na estabilidade oclusal do tratamento da Classe II. Dental Press Journal of Orthodontics, 15, 43-54.

[27] Fink, D.F. and Smith, R.J. (1992) The Duration of Orthodontic Treatment. American Journal of Orthodontics and Dentofacial Orthopedics, 102, 45-51. http://dx.doi.org/10.1016/0889-5406(92)70013-Z

[28] Andrews, L.F. (1972) The Six Keys to Normal Occlusion. American Journal of Orthodontics, 62, 296-309. http://dx.doi.org/10.1016/S0002-9416(72)90268-0

[29] Janson, G., Barros, S.E.C., Freitas, M.R., Henriques, J.F.C. and Pinzan, A. (2007) Class II Treatment Efficiency in Maxillary Premolar Extraction and Nonextraction Protocols. American Journal of Orthodontics and Dentofacial Orthopedics, 132, 490-498. http://dx.doi.org/10.1016/j.ajodo.2005.10.031

[30] McGuinness, N.J.P., Burden, D.J., Hunt, O.T., Johnston, C.D. and Stevenson, M. (2011) Long-Term Occlusal and Soft-Tissue Profile Outcomes after Treatment of Class II Division 1 Malocclusion with Fixed Appliances. American Journal of Orthodontics and Dentofacial Orthopedics, 139, 362-368. http://dx.doi.org/10.1016/j.ajodo.2009.05.035 